\title{
SYNTHESIS, CRYSTAL STRUCTURE AND MAGNETIC BEHAVIOUR OF NOVEL $4 f-2 s$ HETEROMETALIC ONE-DIMENSIONAL COORDINATION POLYMERS ON THE BASE OF 2-FURAN-CARBOXYLIC ACID
}

\author{
Silvia Melnic ${ }^{\mathrm{a}}$, Denis Prodius ${ }^{\mathrm{a}, *}$, Sergiu Shova ${ }^{\mathrm{b}}$, Helen Stoeckli-Evans $^{\mathrm{c}}$, Yurii Simonov ${ }^{\mathrm{b}}$, \\ Alexander Feher ${ }^{d}$, Maria Gdaniec ${ }^{\mathrm{e}}$, Constantin Turta ${ }^{\mathrm{a}}$ \\ ${ }^{a}$ Institute of Chemistry of the ASM, Chisinau, Moldova \\ ${ }^{b}$ Institute of Applied Physics of the ASM, Chisinau, Moldova \\ ${ }^{c}$ Institut de Microtechnique, Neuchâtel, Switzerland \\ ${ }^{d}$ Institute of Inorganic Chemistry, Bratislava, Slovakia \\ ${ }^{e}$ Faculty of Chemistry, A. Mickiewicz University, Poznan, Poland \\ *denis_prodius@yahoo.com,phone: +37322 739722; fax: +373 22739954
}

\begin{abstract}
Nine new complexes with the general formula $\left\{\left[\mathrm{Ln}_{2} \mathrm{Ba}(\alpha-\mathrm{Fur})_{8}\left(\mathrm{H}_{2} \mathrm{O}\right)_{4}\right]\right\}_{\mathrm{n}}$, where $\mathrm{Ln}=\mathrm{Nd}^{3+}, \mathrm{Sm}^{3+}, \mathrm{Eu}^{3+}$, $\mathrm{Pr}^{3+}, \mathrm{Gd}^{3+}, \mathrm{Tb}^{3+}, \mathrm{Ho}^{3+}, \mathrm{Er}^{3+}$ and $\mathrm{La}^{3+} ; \alpha$-Fur $\equiv \mathrm{C}_{4} \mathrm{H}_{3} \mathrm{OCOO}$, were synthesized and characterized by IR spectra, magnetism, X-ray single crystal and powder diffractions. The X-ray diffraction analysis reveals that all titled compounds are isostructural and possess $1 \mathrm{D}$ architecture with $\mathrm{Ln}$ ion in an eight-coordination geometry formed by six oxygen atoms from furoate and two oxygen atoms from water molecules. The magnetic behaviour of several synthesised complexes as well as $\left\{\left[\mathrm{Gd}_{2} \mathrm{Sr}(\alpha-\mathrm{Fur})_{8}\left(\mathrm{H}_{2} \mathrm{O}\right)_{4}\right]\right\}_{\mathrm{n}}$ was investigated in the temperature range of 1.8-300 K. The magnetic data were interpreted in the HDVV approximation with the exchange coupling constant $\mathrm{J}=-0.014 \mathrm{~cm}^{-}$ ${ }^{1}$ that indicates antiferromagnetic interaction in $\left\{\mathrm{Gd}_{2} \mathrm{Sr}\right\}$, whereas a ferromagnetic one $\mathrm{J}=+0.007 \mathrm{~cm}^{-1}$ for $\left\{\mathrm{Gd}_{2} \mathrm{Ba}\right\}$.
\end{abstract}

Keywords: heteronuclear lanthanide (III) complexes, furancarboxylates ligand, crystal structure, magnetic properties.

\section{Introduction}

The syntheses and magnetic properties of rare metal complexes remain an active field of research in recent years, not only for the relevant theoretical interest to investigate the spin-exchange mechanism on the involvement of the $f$ orbital in magnetic interactions, but also for understanding chemical properties, and application of rare earth metal for the synthesis of novel molecular magnets [1-3]. However, the research on molecular materials with lanthanides up to now was mostly focused on the interaction of transition metal with lanthanide ions [4-7], but only few heterometallic complexes with $s$ metal are structurally known and not all of them were magnetically investigated [8].

The search through the Cambridge Crystallographic Data Center (CCDC) [9] reveals that the data on the metal complexes with a 2-furan-carboxylic acid is limited to 37 hits. In the most cases, coordination compounds of transition and other metals are formed owing to the diversity of coordination modes for carboxyl group of the ligand. The exceptions are homo- and heterometalic complexes of $s$ and $s-f$ elements. In the complexes of general formula $\left[\mathrm{M}(\alpha \text {-fur })_{2}\right]$, where $\mathrm{M}=\mathrm{Sr}^{2+}, \mathrm{Ca}^{2+}$, the coordination sphere of metal ions is formed by both tipes of oxigen atoms: carboxilic and from furan ring [10]. The same case was found in [8], where, oxygen atoms of furan rings are involved in coordination of $s$ - element. The topology of the 2-furan-carboxylic acid donor groups is similar to 2pyrydincarboxylic acid, which serves as polidentat ligand, forming a polymer structure with one or more coordination centers [11]. It can be expected the same set of coordination modes for 2-furan-carboxilic acid, despite the fact that 2-pyrydincarboxylic acid is composed of donor nitrogen atom, whose affinity for the $3 \mathrm{~d}$ metals is very high, that determines the mode of coordination.

It was demonstrated [9-14] that the magnetic coupling between Gd(III) ions in Gd(III) dimmers is antiferromagnetic, but recent reports have found ferromagnetic [15-21] interactions. However, the numbers of polynuclear gadolinium compounds for which structural and magnetic data available are quite low and the factors, which govern the nature of $\mathrm{Gd}^{3+}-\mathrm{Gd}^{3+}$ interaction, have not been clarified. In order to fill this lack of knowledge and to understand the specific features of this kind of heteronuclear lanthanide (III) complexes we synthesized and studied (by IR, magnetism, X-ray single crystal and powder diffraction) nine new compounds. The magnetic properties of gadolinium complex have been studied in detail.

\section{Results and discussion}

The X-ray powder diffraction patterns of titled $\left\{\left[\operatorname{Ln}_{2} \mathrm{Ba}(\alpha-\mathrm{Fur})_{8}\left(\mathrm{H}_{2} \mathrm{O}\right)_{4}\right]\right\}_{\mathrm{n}}$ complexes $\left(\mathrm{Ln}=\mathrm{Nd}^{3+}(\mathbf{1}), \mathrm{Sm}^{3+}(\mathbf{2})\right.$, $\mathrm{Eu}^{3+}(\mathbf{3}), \mathrm{Pr}^{3+}(\mathbf{4}), \mathrm{Gd}^{3+}(\mathbf{5}), \mathrm{Tb}^{3+}(\mathbf{6}), \mathrm{Ho}^{3+}(7), \mathrm{Er}^{3+}(\mathbf{8})$ and $\left.\mathrm{La}^{3+}(\mathbf{9})\right)$ shows that they belong to the group of isostructural compounds. It was independently confirmed by the study of single crystal structures of $\mathbf{1}$ and $\mathbf{4}$. Since the complexes are isostructural the characteristic features of the structure is discussed on the base of the compound $\mathbf{1}$ (Fig.1). All complexes are related to one-dimensional (1D) coordination polymers (Fig.2). In the crystal with space group P-1 
the neodymium atom occupies a general position, while Ba atoms reside on the special position - center of inversion. Such an arrangement ensures the formation of the following metal chain along $b$ direction in the crystal

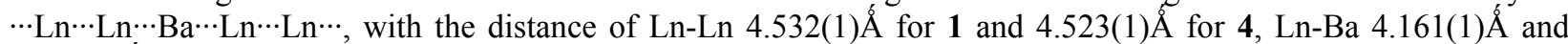
4.151(1)Á, respectively.

The polymer structure is formed owning to the bridge coordination mode of 2-furan-carboxylic acid moieties. Earlier we have noted that the coordination behavior of the furoic acid can be considered as analogue of 2-pyridinecarboxylic acid. So, it can be expected the same set of coordination modes for 2-furan-carboxilic acid, that was discussed in [11]. There are four moieties of 2-furan-carboxylic acid with deprotonated carboxylic groups in the independent unit cell; however their structural role in the crystal is significantly different. One group forms a sin-sin carboxyl bridge and coordinates two lanthanide atoms through oxygen atoms $\mathrm{O} 1$ and $\mathrm{O} 2$ (Fig.1). The bond distances of Ln-O are shown in Table 1. The second 2-furan-carboxylic moiety, marked by oxygen atoms O10 and O11, also bridges two Ln-cations via sin-sin type (Tab.1), but its structural features are more sophisticated. It is a cyclic tetradenthate bridge ligand that forms a single atom (O10) bridge between $\mathrm{Ln}$ and Ba cations and coordinates to Ba through oxygen atom (O12) of a furan ring. Two other 2-furan-carboxylic moieties (O4-O6 and O7-O9) have the same chelating coordination mode and bridges $\mathrm{Ba}$ atom by means of one oxygen atom from furan fragment and one atom from carboxyl group. Simultaneously, they form a monoatomic bridge Ba-O-Ln with distances of Ba-O

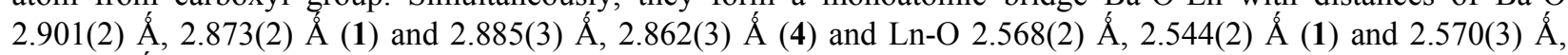
$2.553(3) \AA$ (4). The real coordination modes of 2-furan-carboxylic acid moieties were analyzed in [8]. In the present structure there are three coordination modes - bidentate bridging, through carboxyl groups of the ligand, tridentate chelating-bridging, with the formation of a monoatomic carboxyl bridge M-O-M and tetradentate, which is a superposition of the two previous ones. It have been found that there are no complexes, where-the oxygen atom of furan ring coordinates to $d$ or $f$ - metals.

The Scheme 1 [8] shows that the first and second coordination modes match to $1 \mathrm{a}$ and $1 \mathrm{~b}$ type, and the third to 1c. The lanthanide coordination polyhedron (Fig.2, Tab.1) can be interpreted as Thompson cube with the coordination number of metal equal to 8 . The polyhedron is asymmetrical and built by six oxygen atoms from carboxyl groups of acid moieties and two water molecules. The distances of Ln-O for Nd are within the 2.366$2.568 \AA$ and for $\operatorname{Pr}-2.367-2.570 \AA$ (Tab.1). The water molecules are associated with the distances from 2.457 to 2.506 ̊. The comparison of the lanthanide polyhedrons 1 and $\mathbf{4}$ with that found in [8] for Er shows that they are close except that the contraction of Er-O distance leads to distortions in the polyhedron. The Ba coordination polyhedron is composed by twelve oxygen atoms from acid moieties. The distances are given in Tab.1. By means of hydrogen bonds the polymer chains form a three-dimensional frame in the crystal (Fig.3). There are two water molecules in the independent unite cell. All protons are involved in hydrogen bonds (Tab.2), with one water molecule forms a link inside the polymer chain, whereas the second one between the chains.

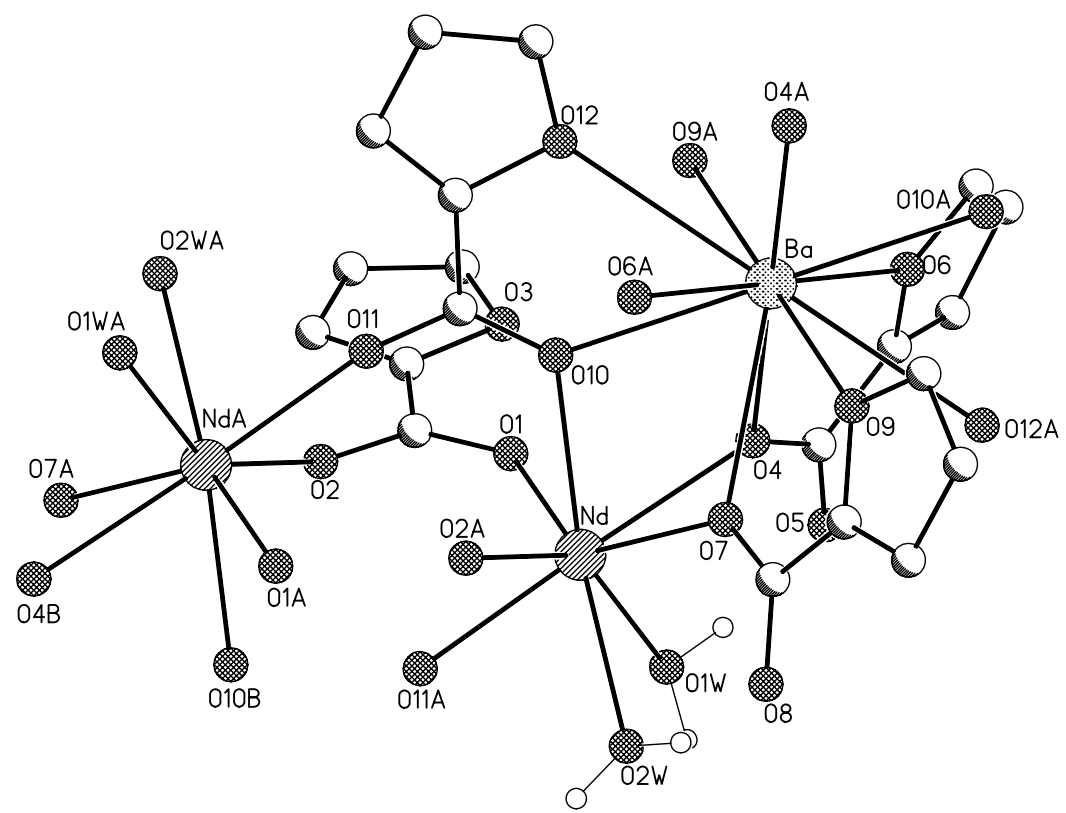

Fig . 1. Structure of the unsymmetrical fragment of the coordination polymer in 1. 


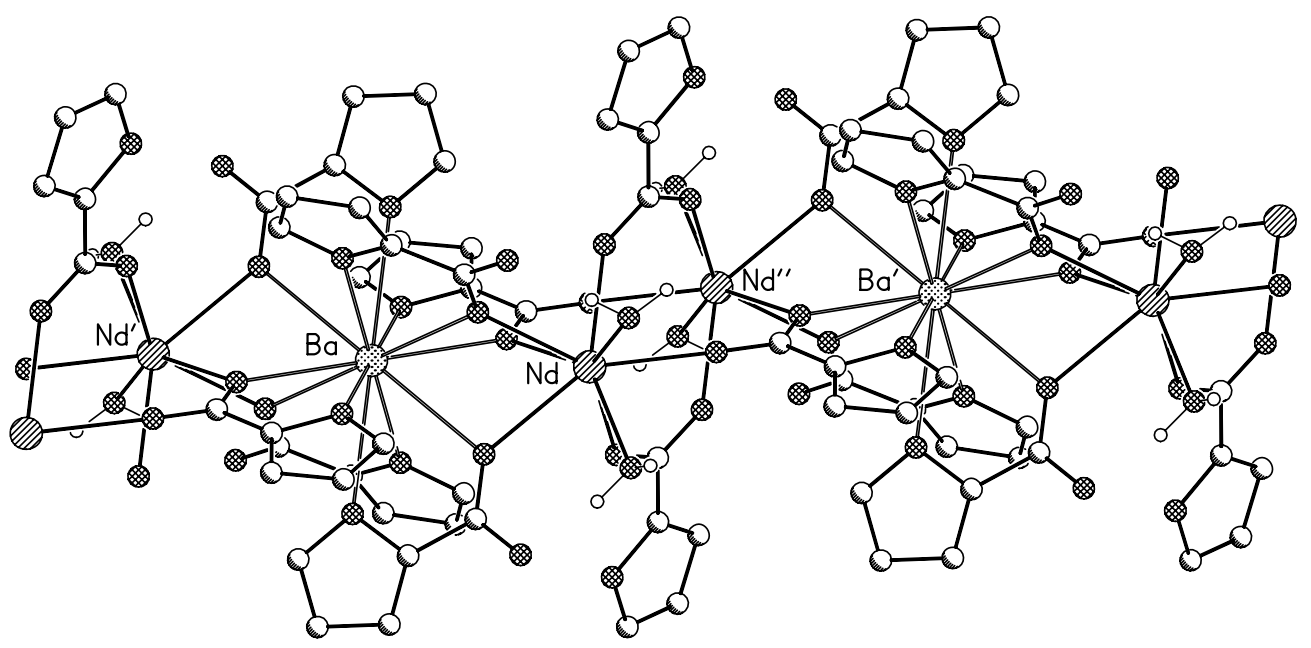

Fig. 2. The fragment of coordination polymer in $\left\{\left[\mathrm{Nd}_{2} \mathrm{Ba}(\alpha-\mathrm{Fur})_{8}\left(\mathrm{H}_{2} \mathrm{O}\right)_{4}\right]\right\}_{\mathrm{n}}$.

Bond lengths and bond angles for compounds 1 and 2

Table 1

\begin{tabular}{|c|c|c|}
\hline \multirow{2}{*}{ Bond } & \multicolumn{2}{|c|}{$d, \AA$} \\
\hline & $1(\mathrm{M}=\mathrm{Nd})$ & $4(\mathrm{M}=\mathrm{Pr})$ \\
\hline $\mathrm{M}-\mathrm{O} 2$ & $2.366(2)$ & $2.367(3)$ \\
\hline M-O11 & $2.395(2)$ & $2.397(4)$ \\
\hline M-O1 & $2.443(2)$ & $2.444(4)$ \\
\hline $\mathrm{M}-\mathrm{O} 1 w$ & $2.464(2)$ & $2.457(4)$ \\
\hline M-O10 & $2.489(2)$ & $2.487(3)$ \\
\hline $\mathrm{M}-\mathrm{O} 2 w$ & $2.506(2)$ & $2.503(3)$ \\
\hline M-O7 & $2.544(2)$ & $2.553(3)$ \\
\hline M-O4 & $2.568(2)$ & $2.570(3)$ \\
\hline Ba-O10 & $2.757(2)$ & $2.738(3)$ \\
\hline Ba-O9 & $2.865(2)$ & $2.848(4)$ \\
\hline Ba-O7 & 2.873() & $2.862(3)$ \\
\hline Ba-O4 & $2.901(2)$ & $2.885(3)$ \\
\hline $\mathrm{Ba}-\mathrm{O} 6$ & $2.943(2)$ & $2.924(3)$ \\
\hline Ba-O12 & $3.015(2)$ & $2.996(4)$ \\
\hline \multirow{2}{*}{ Angle } & \multicolumn{2}{|c|}{$\omega$, deg } \\
\hline & $\mathbf{1}(\mathrm{M}=\mathrm{Nd})$ & $4(\mathrm{M}=\mathrm{Pr})$ \\
\hline $\mathrm{M}-\mathrm{O} 4-\mathrm{Ba}$ & $98.91(6)$ & $98.9(1)$ \\
\hline M-O7-Ba & $100.19(6)$ & $100.0(1)$ \\
\hline M-O10-Ba & $104.86(6)$ & $105.1(1)$ \\
\hline
\end{tabular}

Geometric parameters of hydrogen bonds in the structure 1

Table 2

\begin{tabular}{|c|c|c|c|c|c|}
\hline Donor (D) & Acceptor (A) & Symmetry codes & $\mathrm{R}(\mathrm{D} \cdots \mathrm{A})$ & $\mathrm{H} \cdots \mathrm{A}$ & DHA angle, deg \\
\hline $\mathrm{O} 1 \mathrm{w}$ & 05 & $\begin{array}{lll}-x & 1-y & -z\end{array}$ & $2,875(5)$ & 2,07 & 149 \\
\hline O1w & 05 & $\begin{array}{lll}x & y & z\end{array}$ & $2,640(7)$ & 1,77 & 167 \\
\hline $\mathrm{O} 2 \mathrm{w}$ & 08 & $-x \quad 1-y \quad 1-z$ & $2,927(6)$ & 2,29 & 128 \\
\hline $\mathrm{O} 2 \mathrm{w}$ & 08 & $\begin{array}{lll}x & y & z\end{array}$ & $2,621(7)$ & 1,77 & 158 \\
\hline
\end{tabular}




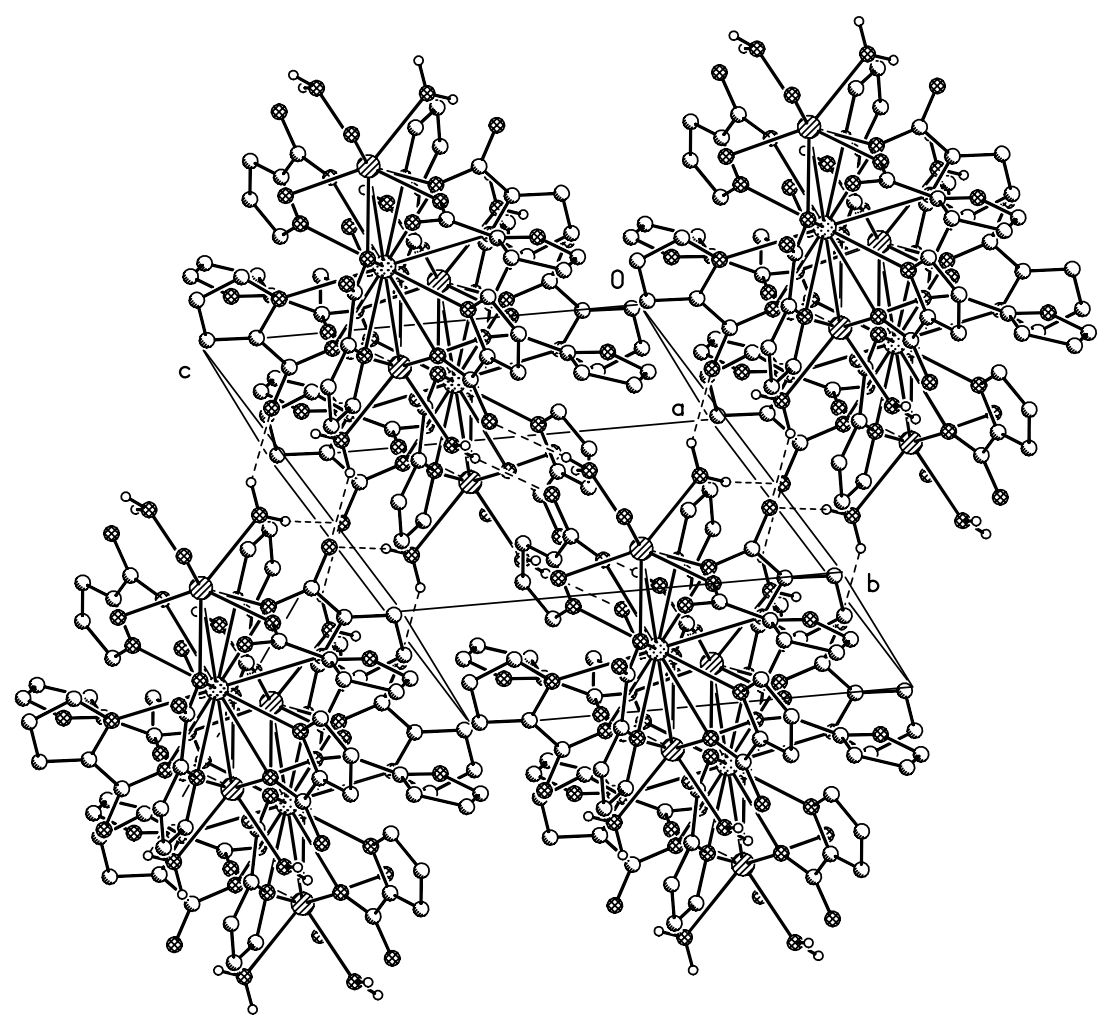

Fig. 3. Projectional view of cell along $b$ axis for 1 .

Being interested in the magnetic behaviour of the complexes, variable-temperature $(1.8-300 \mathrm{~K})$ magnetic susceptibility data were collected for $\left\{\left[\mathrm{Nd}_{2} \mathrm{Ba}(\alpha-\mathrm{Fur})_{8}\left(\mathrm{H}_{2} \mathrm{O}\right)_{4}\right]\right\}_{\mathrm{n}}(1), \quad\left\{\left[\mathrm{Pr}_{2} \mathrm{Ba}(\alpha-\mathrm{Fur})_{8}\left(\mathrm{H}_{2} \mathrm{O}\right)_{4}\right]\right\}_{\mathrm{n}}(4), \quad\left\{\left[\mathrm{Gd}_{2} \mathrm{Ba}(\alpha-\right.\right.$ Fur $\left.\left.)_{8}\left(\mathrm{H}_{2} \mathrm{O}\right)_{4}\right]\right\}_{\mathrm{n}}(5)$ and $\left\{\left[\mathrm{Gd}_{2} \mathrm{Sr}(\alpha-\mathrm{Fur})_{8}\left(\mathrm{H}_{2} \mathrm{O}\right)_{4}\right]\right\}_{\mathrm{n}}(10)$. complexes, and the results are shown in the form of plots of $\chi_{\mathrm{M}}$ vs. T and denote magnetic susceptibility per molecule (Fig. 4, for 1 and 4).

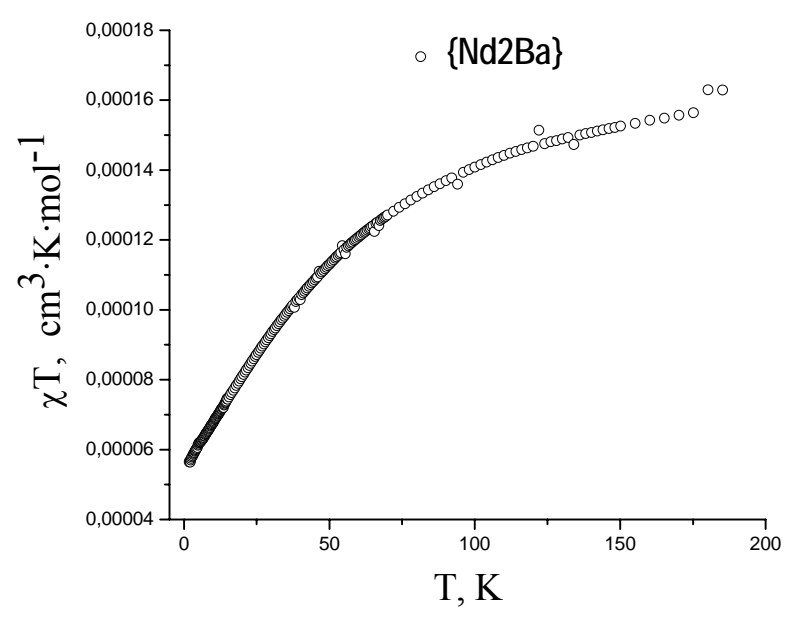

a)

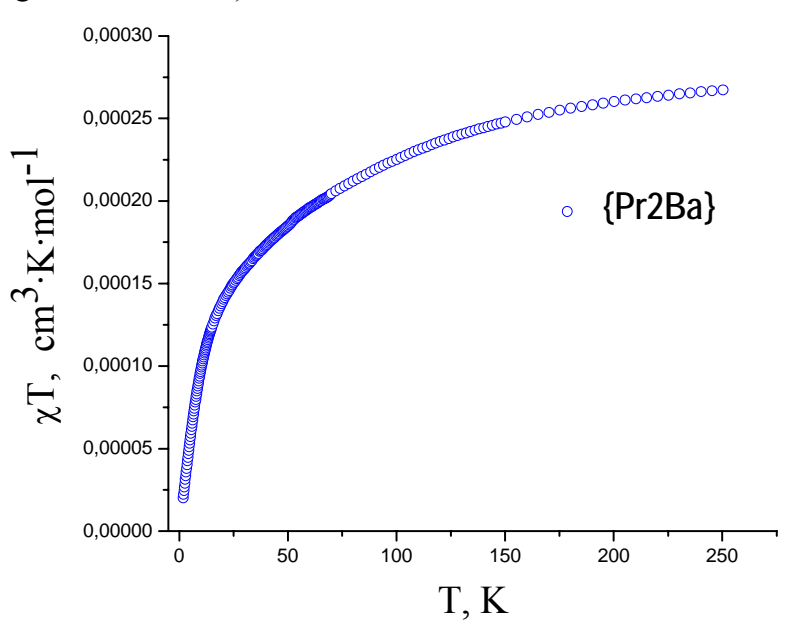

b)

Fig.4. $\chi T$ versus $T$ plot for complexes:

$\left\{\left[\mathrm{Nd}_{2} \mathrm{Ba}(\alpha-\mathrm{Fur})_{8}\left(\mathrm{H}_{2} \mathrm{O}\right)_{4}\right]\right\}_{\mathrm{n}}(\mathbf{1})$ (a) and $\left\{\left[\operatorname{Pr}_{2} \mathrm{Ba}(\alpha-\mathrm{Fur})_{8}\left(\mathrm{H}_{2} \mathrm{O}\right)_{4}\right]\right\}_{\mathrm{n}}(4)(\mathrm{b})$.

When the rare earth ions different from $\mathrm{Gd}^{3+}$ are characterized by orbitally degenerate ground state, the analysis of their magnetic behavior is not straightforward. The best fit of the experimental and theoretical data can be obtained at framework of a classical Crystal Field approach for $\operatorname{Pr}^{3+}, \mathrm{Nd}^{3+}$ derivatives assuming a pseudo $\mathrm{D}_{4}$ symmetry with the aim to reduce the number of parameters [8]. In this paper we were interested in magnetic data analysis only of gadolinium containing complexes. The reason for the choice of gadolinium is because Gd(III) ion and its complex are quite simple for a magnetic study. The $\mathrm{Gd}^{3+}$ ion has an ${ }^{8} \mathrm{~S}_{7 / 2}$ ground state, which is located at some $3 \times 10^{4} \mathrm{~cm}^{-1}$ below the first excited state and is not perturbed by crystal field effects, and has no orbital angular momentum and the anisotropic effect [25]. Based on the inherent nature of $\mathrm{Gd}(\mathrm{III})$, the complex $\left\{\left[\mathrm{Gd}_{2} \mathrm{Ba}(\alpha-\mathrm{Fur})_{8}\left(\mathrm{H}_{2} \mathrm{O}\right)_{4}\right]\right\}_{\mathrm{n}}$ and $\left\{\left[\mathrm{Gd}_{2} \mathrm{Sr}(\alpha-\mathrm{Fur})_{8}\left(\mathrm{H}_{2} \mathrm{O}\right)_{4}\right]\right\}_{\mathrm{n}}$ are ideal models for studying the magnetic interaction between $\mathrm{Ln}(\mathrm{III})$ ions among all title complexes. 
The analysis of the measured effective Bohr magneton number $\left(\mu_{\mathrm{eff}}\right)$ for $\mathbf{5}$ in the temperature range between 1.8 and $300 \mathrm{~K}$ shows that with the decrease of the temperature, $\mu_{\text {eff }}$ increases slowly reaching a maximum value of 11.0 at $3 \mathrm{~K}$, which is slightly less than the spin-only value, 11.23 B.M., calculated from the equation $\mu_{\text {eff }}=\left(\mu_{\text {Gd(III) }}^{2}+\right.$ $\left.\mu_{\text {Gd(III) }}^{2}\right)^{1 / 2}$, in the absence of exchange interaction for a binuclear $\operatorname{Gd}(\mathrm{III})\left(\mathrm{S}_{1}=\mathrm{S}_{2}=7 / 2\right)$ system. This behaviour is characteristic for weak intramolecular ferromagnetic spin-exchange interaction between the paramagnetic ions in the complex. But the analysis of magneton number for $\mathbf{1 0}$ indicates antiferromagnetic interaction.

In order to further assess the strength of this magnetic interaction quantitatively, a magnetic analysis was performed with the susceptibility equation based on the Heisenberg spin-exchange operator:

$$
\hat{\mathrm{H}}=-2 \mathrm{~J} \hat{\mathrm{S}}_{1} \cdot \hat{\mathrm{S}}_{2}
$$

where the exchange parameter $\mathrm{J}$ is negative for an antiferromagnetic and positive for a ferromagnetic interaction. For the $\mathrm{Gd}(\mathrm{III})$ - $\mathrm{Gd}(\mathrm{III})\left(\mathrm{S}_{1}=\mathrm{S}_{2}=7 / 2\right)$ system, the theoretical expression of magnetic susceptibility is easily derived from (1):

$$
\mathrm{X}_{\mathrm{M}}=\frac{\mathrm{N} \beta^{2} \mathrm{~g}^{2}}{3 \mathrm{kT}}\left[\frac{A}{B}\right]
$$

where $\quad A=840 \exp (56 x)+546 \exp (42 x)+330 \exp (30 x)+180 \exp (20 x)+84 \exp (12 x)+30 \exp (6 x)+6 \exp (2 x)$; $\mathrm{B}=15 \exp (56 \mathrm{x})+13 \exp (42 \mathrm{x})+11 \exp (30 \mathrm{x})+9 \exp (20 \mathrm{x})+7 \exp (12 \mathrm{x})+5 \exp (6 \mathrm{x})+3 \exp (2 \mathrm{x})+1 ; \mathrm{x}=-\mathrm{J} / \mathrm{kT}$, and $\chi_{M}$ is the molecular susceptibility per complex and the remaining symbols have their usual meaning.

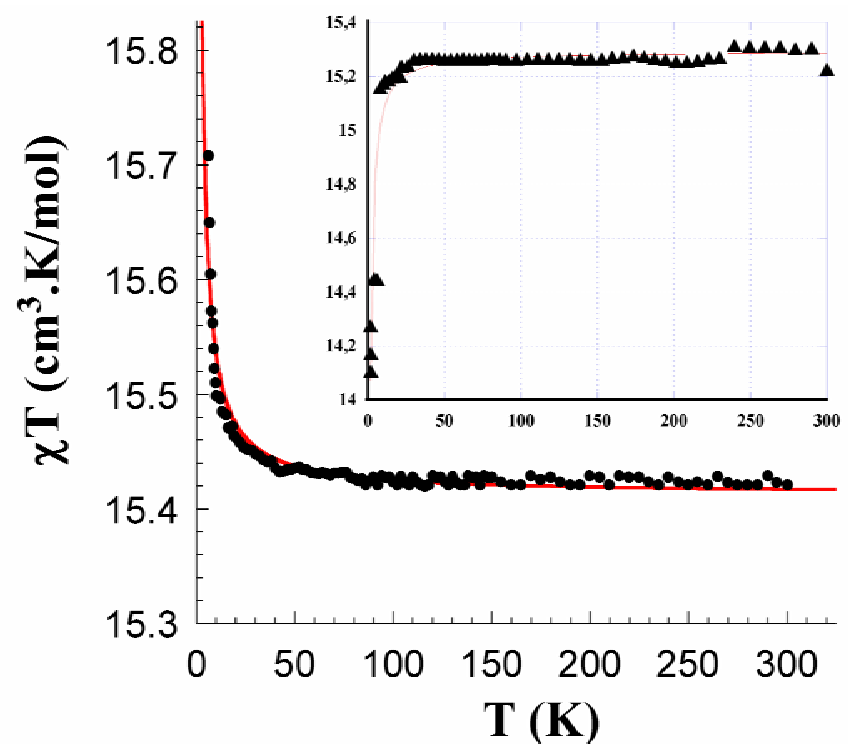

Fig. 5. $\chi T$ versus $T$ plot for complexes:

$\left\{\left[\operatorname{Gd}_{2} \mathrm{Ba}(\alpha-\mathrm{Fur})_{8}\left(\mathrm{H}_{2} \mathrm{O}\right)_{4}\right]\right\}_{\mathrm{n}}(5)$ and $\left\{\left[\mathrm{Gd}_{2} \mathrm{Sr}(\alpha-\mathrm{Fur})_{8}\left(\mathrm{H}_{2} \mathrm{O}\right)_{4}\right]\right\}_{\mathrm{n}}(10)$ (insert).
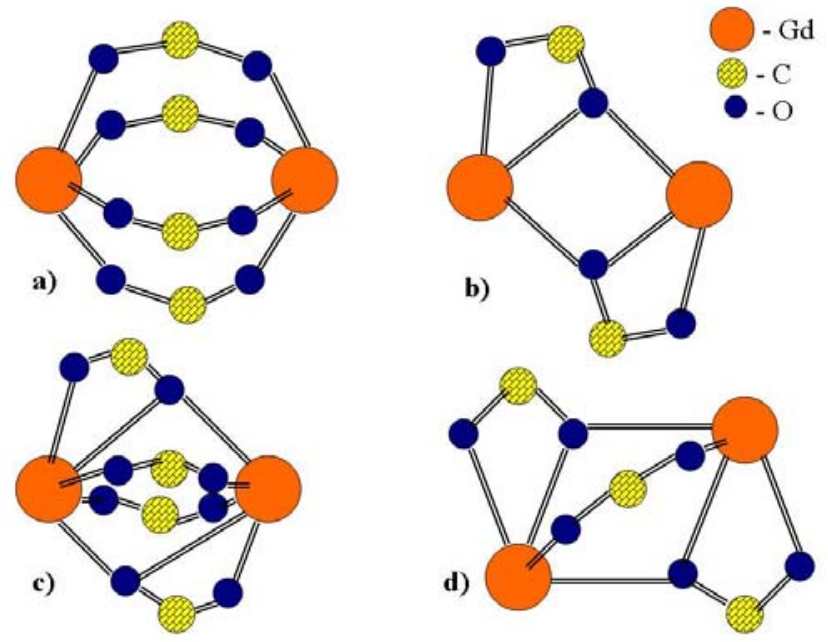

As shown in Fig. 5, good least-square fits to the experimental data were obtained for $\mathrm{J}=+0,007 \mathrm{~cm}^{-1}$ and $\mathrm{g}=1.98$. This results indicate that the complex undergoes a weak ferromagnetic super exchange interaction between Gd(III) - Gd(III) ions.

The analysis of literature [13-17] shows that the different kind of interaction in Gd complexes might be due to the type of the bridging in $\mathrm{Gd}^{3+}-\mathrm{Gd}^{3+}$ dimmers. Four different homodinuclear units (Fig.6) in $\mathrm{Gd}^{3+}$ carboxylates are known. In these units the $\mathrm{Gd}^{3+}$ ions are bridged to dimmers by carboxylate groups in a bidentate or tridentate fashion. Beside the pure bridging motifs $\mathbf{a}$ and $\mathbf{b}$, where only bidentate or tridentate modes are involved; there are two other in which both modes are involved (motifs $\mathbf{c}$ and d). As was reported, antiferromagnetic interactions are found for motifs a and $\mathbf{c}$, and a ferromagnetic one for motifs $\mathbf{b}$ and $\mathbf{d}$ [17].

Fig. 6. Bridging motifs in homodinuclear $\mathrm{Gd}^{3+}$ carboxylates; (a) for carboxylate groups bridged in a bidentate fashion, (b) two groups bridged in a tridentate fashion, (c) two carboxylate groups bridged in a bidentate, two in a tridentate mode, (d) two carboxylate groups bridged in a tridentate, one in a bidentate fashion. 
The values of $\mathbf{J}$ and $\mathrm{Gd}^{3+}-\mathrm{Gd}^{3+}$ distances in the compound $\mathbf{1 0}$ are comparable with the ones for other carboxylates contain Gd. The analysis of this complex shows that it is in a good concordance with data given in literature [23-24]. In the compound 10 carboxylate groups bridge the $\mathrm{Gd}^{3+}$ ions in a bidentate bridging mode (a), that leads to a negative exchange parameter $\mathrm{J}=-0,014 \mathrm{~cm}^{-1}$ and indicates a antiferromagnetic interaction. But in the case of 5, in spite of bridging of $\mathrm{Gd}^{3+}$ ions in a (a) fashion, a ferromagnetic interaction was observed. The detailed comparable analysis of $\mathbf{5}$ and $\mathbf{1 0}$ shown that $\left\{\mathrm{Gd}_{2} \mathrm{Sr}\right\}$ has a rather symmetrical environment, but angles of $\left\{\mathrm{Gd}_{2} \mathrm{Ba}\right\}$ are quite differ (Table 3).

Table 3

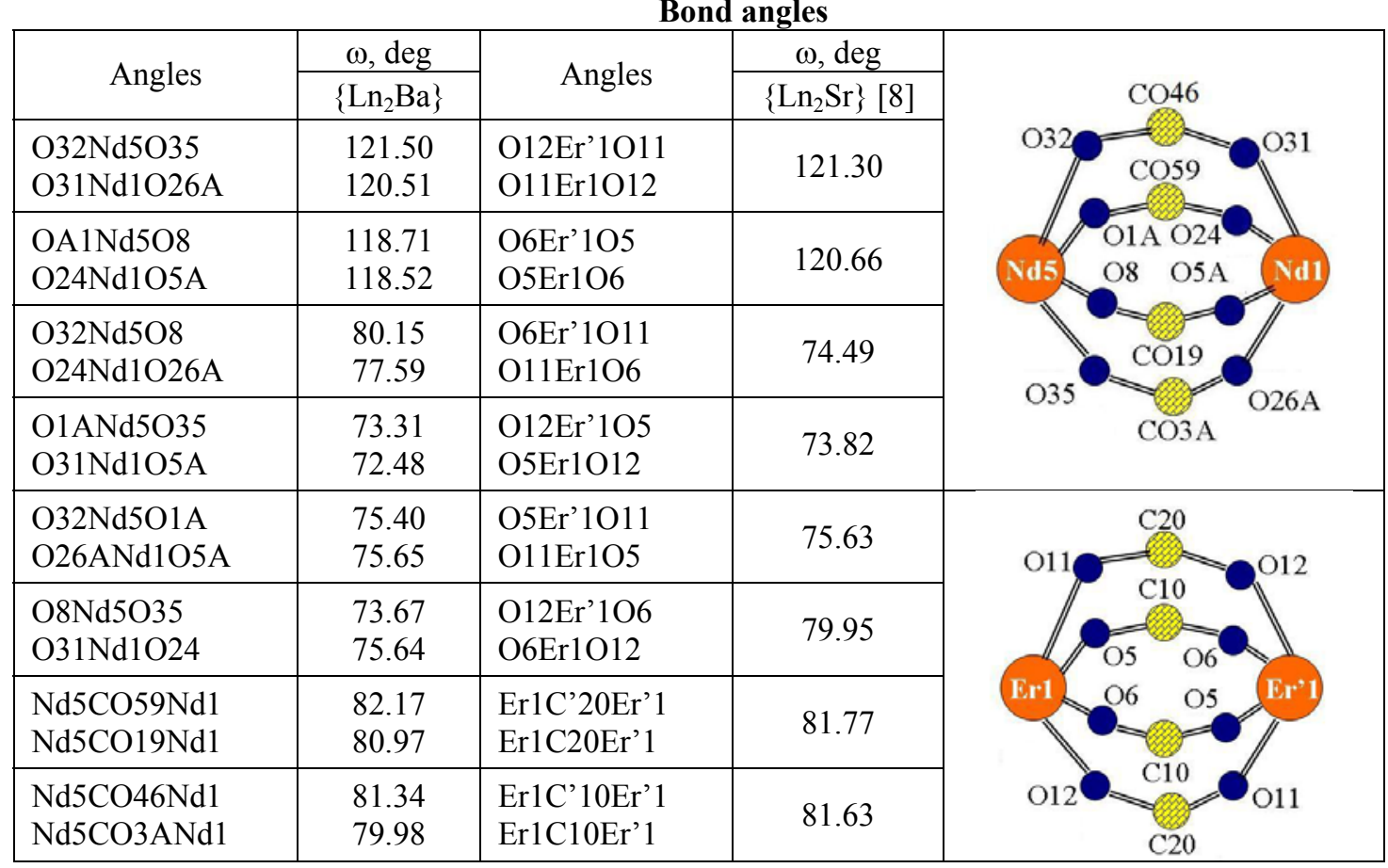

\section{Conclusions}

Nine new complexes with the general formula $\left\{\left[\mathrm{Ln}_{2} \mathrm{Ba}(\alpha-\mathrm{Fur})_{8}\left(\mathrm{H}_{2} \mathrm{O}\right)_{4}\right]\right\}_{\mathrm{n}}$, where $\mathrm{Ln}=\mathrm{Nd}^{3+}(\mathbf{1}), \mathrm{Sm}^{3+}(\mathbf{2}), \mathrm{Eu}^{3+}$ (3), $\operatorname{Pr}^{3+}(4), \mathrm{Gd}^{3+}(\mathbf{5}), \mathrm{Tb}^{3+}(\mathbf{6}), \mathrm{Ho}^{3+}(\mathbf{7}), \operatorname{Er}^{3+}(\mathbf{8})$ and $\mathrm{La}^{3+}(\mathbf{9}) ; \alpha-\mathrm{Fur} \equiv \mathrm{C}_{4} \mathrm{H}_{3} \mathrm{OCOO}$, were synthesized and characterized by IR spectra, magnetism, X-ray single crystal and powder diffractions. The complexes possess a 1D architecture with Ln ion in a eight-coordination geometry formed by six oxygen atoms from furoate and two oxygen atoms from aqua ligands. The oxygen atom of furan ring coordinates to $s$ - metals only. The magnetic data were interpreted in the HDVV approximation with the exchange coupling constant $\mathrm{J}=-0.014 \mathrm{~cm}^{-1}$ that indicates antiferromagnetic interaction in $\mathbf{1 0}$, whereas a ferromagnetic one $\mathrm{J}=+0.007 \mathrm{~cm}^{-1}$ for $\mathbf{5}$. We suppose that not only the bridging modes of the carboxylate groups influence on the occurrence of ferro-, and antiferromagnetic interaction, but also the distortion among bridging motifs should be taken in consideration.

\section{Experimental}

Material. 2-Furoic acid (Aldrich, $>98 \%$ ) was purified by re-crystallization from water/methanol [26]. The starting materials were $\mathrm{Ba}\left(\mathrm{C}_{4} \mathrm{H}_{3} \mathrm{OCOO}\right)_{2} \cdot \mathbf{4} \mathrm{H}_{2} \mathrm{O}$ and $\mathrm{Ln}\left(\mathrm{ClO}_{4}\right)_{3} \cdot \mathbf{6} \mathrm{H}_{2} \mathrm{O}\left(\mathrm{Ln}=\mathrm{Nd}^{3+}, \mathrm{Sm}^{3+}, \mathrm{Eu}^{3+}, \mathrm{Pr}^{3+}, \mathrm{Gd}^{3+}, \mathrm{Tb}^{3+}\right.$, $\left.\mathrm{Ho}^{3+}, \mathrm{Er}^{3+}, \mathrm{La}^{3+}\right) . \mathbf{B a}\left(\mathrm{C}_{4} \mathrm{H}_{3} \mathrm{OCOO}\right)_{2} \cdot 4 \mathrm{H}_{2} \mathrm{O}$ was synthesized by reaction between $\mathrm{BaCO}_{3}$ and 2-furoic acid.

$\mathrm{Ln}\left(\mathrm{ClO}_{4}\right)_{3} \cdot 6 \mathrm{H}_{2} \mathrm{O}$ was prepared by dissolving the respective lanthanide oxides $(99.9 \%$ pure $)$ in ca. $50 \% \mathrm{HClO}_{4}$ and then recrystallizing the resulting salt by evaporating the aqueous solution on a water bath.

CAUTION: perchlorate salts are potentially explosive and were handled with great care.

Synthesis of $\left\{\left[\mathrm{Ln}_{2} \mathrm{Ba}(\alpha-\mathrm{Fur})_{8}\left(\mathrm{H}_{2} \mathrm{O}\right)_{4}\right]\right\}_{n}$, (where $\mathrm{Ln}=\mathrm{Nd} \mathrm{d}^{3+}$ (1), $\mathrm{Sm}^{3+}$ (2), $\mathrm{Eu}^{3+}$ (3), $\mathrm{Pr}^{3+}$ (4), $\mathrm{Gd}^{3+}$ (5), $\mathrm{Tb}^{3+}$ (6), $\mathrm{Ho}^{3+}$ (7), $\mathrm{Er}^{3+}$ (8) and $\left.\mathrm{La}^{3+}(9) ; \alpha-F u r \equiv \mathrm{C}_{4} \mathrm{H}_{3} \mathrm{OCOO}\right)$. All the nine heterometalic complexes were prepared in a similar fashion and the preparation of $\left\{\left[\mathrm{Nd}_{2} \mathrm{Ba}(\alpha-\mathrm{Fur})_{8}\left(\mathrm{H}_{2} \mathrm{O}\right)_{4}\right]\right\}_{\mathrm{n}}$ is presented here as an example. Solutions of $\mathrm{Ba}\left(\mathrm{C}_{4} \mathrm{H}_{3} \mathrm{OCOO}\right)_{2} \cdot 4 \mathrm{H}_{2} \mathrm{O}(0.30 \mathrm{~g}, 0.70 \mathrm{mmol})$ in $10 \mathrm{~mL}$ of water and $\mathrm{Nd}\left(\mathrm{ClO}_{4}\right)_{3} \cdot 6 \mathrm{H}_{2} \mathrm{O}(0.40 \mathrm{~g}, 0.70 \mathrm{mmol})$ in $15 \mathrm{~mL}$ of ethanol were stirred until formation of lilac gel-mass. After 10 days a violet microcrystalline product was filtered off, quickly washed with water and air-dried. Yield: $60 \%$ (on Nd basis). (1) Calc. for $\mathrm{C}_{40} \mathrm{H}_{32} \mathrm{O}_{28} \mathrm{Nd}_{2} \mathrm{Ba}: \mathrm{C}, 34.65 ; \mathrm{H}$, 2.33; Ba, 9.90\%. Found: C, 34.57; H, 2.36; Ba, 10.1\%. IR (KBr): v/ $\mathrm{cm}^{-1}: 3500 \mathrm{~b}, 1627 \mathrm{~m}, 1586 \mathrm{vs}, 1221 \mathrm{~m}, 1202 \mathrm{~s}$, $1136 \mathrm{w}, 1072 \mathrm{~s}, 1007 \mathrm{~s}, 933 \mathrm{~m}, 883 \mathrm{~m}, 761 \mathrm{~s}, 753 \mathrm{w}, 611 \mathrm{w}, 598 \mathrm{~m}, 460 \mathrm{~s}$. The IR spectra of other complexes have the same characteristic bands. (2) Calc. for $\mathrm{C}_{40} \mathrm{H}_{32} \mathrm{O}_{28} \mathrm{Sm}_{2} \mathrm{Ba}$ : C, 34.35; H, 2.31; Ba, 9.82\%. Found: C, 34.18; H, 2.35; 
Ba, 9.78\%.(3) Calc. for $\mathrm{C}_{40} \mathrm{H}_{32} \mathrm{O}_{28} \mathrm{Eu}_{2} \mathrm{Ba}$ : C, 34.26; H, 2.30; Ba, 9.79\%. Found: C, 33.93; H, 2.36; Ba, 9.80\%. (4) Calc. for $\mathrm{C}_{40} \mathrm{H}_{32} \mathrm{O}_{28} \mathrm{Pr}_{2} \mathrm{Ba}$ : C, 34.82; H, 2.34; Ba, 9.95\%. Found: C, 34.70; H, 2.36; Ba, 9.93\%.(5) Calc. for $\mathrm{C}_{40} \mathrm{H}_{32} \mathrm{O}_{28} \mathrm{Gd}_{2} \mathrm{Ba}$ : C, 34.01; H, 2.28; Ba, 9.72\%. Found: C, 33.93; H, 2.35; Ba, 9.71\%.(6) Calc. for $\mathrm{C}_{40} \mathrm{H}_{32} \mathrm{O}_{28} \mathrm{~Tb}_{2} \mathrm{Ba}$ : C, 33.93; H, 2.27; Ba, 9.69\%. Found: C, 33.37; H, 2.33; Ba, 9.55\%.(7) Calc. for $\mathrm{C}_{40} \mathrm{H}_{32} \mathrm{O}_{28} \mathrm{Ho}_{2} \mathrm{Ba}$ : C, 33.65; H, 2.26; Ba, 9.63\%. Found: C, 33.32; H, 2.29; Ba, 9.53\%.(8) Calc. for $\mathrm{C}_{40} \mathrm{H}_{32} \mathrm{O}_{28} \mathrm{Er}_{2} \mathrm{Ba}: \mathrm{C}, 33.54 ; \mathrm{H}, 2.25 ; \mathrm{Ba}, 9.59 \%$. Found: C, 32.91; H, 2.34; Ba, 9.42\%.(9) Calc. for $\mathrm{C}_{40} \mathrm{H}_{32} \mathrm{O}_{28} \mathrm{Ln}_{2} \mathrm{Ba}$ : C, 34.92; H, 2.34; Ba, 9.98\%. Found: C, 34.25; H, 2.42; $\mathrm{Ba}, 9.80 \%$.

Synthesis of $\left\{\left[\mathrm{Gd}_{2} \mathrm{Sr}(\alpha-\mathrm{Fur})_{8}\left(\mathrm{H}_{2} \mathrm{O}\right)_{4}\right]\right\}_{n}$ (10) was performed conform the procedure described in [8]. Yield: 61 \% (on Gd basis). Calc. for $\mathrm{C}_{40} \mathrm{H}_{35} \mathrm{O}_{29.5} \mathrm{Gd}_{2} \mathrm{Sr}$ : C, 34.59; H, 2.54; Sr, 6.30\%. Found: C, 34.67; H, 2.51; Sr, 6.10\%. IR $\left(\mathrm{cm}^{-1}\right): \mathrm{v} / \mathrm{cm}^{-1}: 3500 \mathrm{~b}, 1625 \mathrm{~m}, 1580 \mathrm{vs}, 1230 \mathrm{~m}, 1200 \mathrm{~s}, 1140 \mathrm{w}, 1070 \mathrm{~s}, 1010 \mathrm{~s}, 940 \mathrm{~m}, 880 \mathrm{~m}, 820 \mathrm{w}, 765 \mathrm{~s}, 720 \mathrm{w}, 615 \mathrm{w}$, $595 \mathrm{~m}, 470 \mathrm{~s}$.

Physical measurements. The carbon and hydrogen content of complex was determined by standard micromethods in the group of microanalysis of the Institute of Chemistry on Vario-EL-III-CHNOS Elemental Analyzer and barium determination was carry out using the Atomic Absorption Spectroscopy (Spectrophotometer AAS-3N Karl Zeiss Jena ${ }^{\circledR}$ DDR) in the Metrology and Analytical Methods of Research Centre of the Academy of Sciences of Moldova.

IR spectrum of each polycrystalline sample was recorded on a Perkin Elmer Spectrum 100 FT-IR Spectrometer.

The magnetic measurements were carried out using a Quantum Design SQUID magnetometer MPMS-XL between 1.8 and $300 \mathrm{~K}$ on polycrystalline samples (UT, Karlsruhe). The magnetic data were corrected for the sample holder and the diamagnetic contribution estimated from Pascal constants.

Crystallographic measurements for 1 were carried out at $130 \mathrm{~K}$ on KUMA-4CCD diffractometer (Mo-K $\alpha$ radiation) from a shapeless block of single crystal with the linear dimensions $0.3 \times 0.4 \times 0.2 \mathrm{~mm}$. The crystal was placed $60 \mathrm{~mm}$ from the CCD detector chamber. More than hemisphere of reciprocal space was covered by combination of three sets of exposures; each set had a different $\varphi$-angle $(0,90,270)$ and each exposure of $30 \mathrm{~s}$ covered $0.75^{\circ}$ in $\omega$. The unit cell determination and data integration were carried out using the CrysAlis package of Oxford Diffraction [27]. Intensity data were corrected for the Lorentz and polarization effects.

The X-ray data for $\mathbf{4}$ were collected on a STOE Imaging Plate Diffractometer System (IPDS) equipped with an Oxford Cryosystems cooler device using a graphite monochromator $(\lambda=0.71073 \AA)$. Data were collected [28] using $\varphi$ rotation movement with the crystal-to-detector distance equal to $70 \mathrm{~mm}\left(\varphi=0.0-200_{-}, \Delta \varphi=1.0^{\circ}\right.$. All the structure was solved by direct methods [29] and refined by full-matrix least-squares on $F^{2}$ with anisotropic displacement parameters for non- $\mathrm{H}$ atoms [30]. The hydrogen atoms attached to carbon were included in idealized position in a riding model with isotropic temperature factor fixed at $1.2 \times \mathrm{U}_{\mathrm{eq}}$ of the relevant carbon atom. Positional parameters of $\mathrm{H}$-atoms of the water molecules were verified by the geometric parameters of the corresponding hydrogen bonds.

The absorption correction was introduced by a semi-empirical method from symmetry equivalent reflections [31]. Scattering factors were taken from the standard compilation [32]. The molecular plots were obtained by using the ZORTEP program [33]. The crystal data and details of the refinement of $\mathbf{1}$ and $\mathbf{4}$ are summarized in Table 4, while selected bond lengths and angles - in Table 1.

Table 4

Crystallographic characteristics of the $\left\{\left[\mathrm{Nd}_{2} \mathrm{Ba}(\alpha-\mathrm{Fur})_{8}\left(\mathrm{H}_{2} \mathrm{O}\right)_{4}\right]\right\}_{n}(1)$ and $\left\{\left[\mathrm{Pr}_{2} \mathrm{Ba}(\alpha-\mathrm{Fur})_{8}\left(\mathrm{H}_{2} \mathrm{O}\right)_{4}\right]\right\}_{n}(4)$ complexes

\begin{tabular}{|c|l|c|}
\hline Characteristic & \multicolumn{1}{|c|}{1} & 4 \\
\hline Empirical formula & $\mathrm{C}_{40} \mathrm{H}_{32} \mathrm{O}_{28} \mathrm{Nd}_{2} \mathrm{Ba}$ & $\mathrm{C}_{40} \mathrm{H}_{32} \mathrm{O}_{28} \mathrm{Pr}_{2} \mathrm{Ba}$ \\
\hline $\mathrm{FW}$ & 1386.48 & 1379.82 \\
\hline Wavelength, $\AA$ & 0.71073 & 0.71073 \\
\hline $\mathrm{T}, \mathrm{K}$ & 293 & 293 \\
\hline Space group & $\mathrm{P} \overline{1}$ & $\mathrm{P} \overline{1}$ \\
\hline$a, \AA$ & 10.7619 & 10.7322 \\
\hline$b, \AA$ & 11.232 & 11.1618 \\
\hline$c, \AA$ & 11.6542 & 11.5103 \\
\hline$\alpha$, deg & 117.851 & 117.751 \\
\hline$\beta, \operatorname{deg}$ & 93.654 & 93.603 \\
\hline$\gamma, \operatorname{deg}$ & 108.966 & 108.948 \\
\hline $\mathrm{V}, \AA^{3}$ & 1138.12 & 1115.74 \\
\hline
\end{tabular}




\begin{tabular}{|l|c|c|}
\hline \multicolumn{1}{|c|}{$Z, \rho_{\text {(calcd.) }}, \mathrm{g} / \mathrm{cm}^{3}$} & $1,2.023$ & $1,2.054$ \\
\hline$\mu_{\mathrm{Mo}}, \mathrm{mm}^{-1}$ & 3.202 & 3.123 \\
\hline Crystal size, $\mathrm{mm}$ & $0.6 \times 0.15 \times 0.05$ & $0.5 \times 0.25 \times 0.20$ \\
\hline$\theta$ range, deg & 2.69 to 29.76 & 2.08 to 25.96 \\
\hline $\begin{array}{l}\text { Number of reflections: } \\
\text { measured/unique }\end{array}$ & $\begin{array}{c}12003 / 5480 \\
(R(\mathrm{int})=0.0185)\end{array}$ & $\begin{array}{c}8668 / 4053 \\
(\mathrm{R}(\mathrm{int})=0.0942)\end{array}$ \\
\hline $\begin{array}{l}\text { Number of refined } \\
\text { parameters }\end{array}$ & 317 & 322 \\
\hline $\mathrm{GOOF}$ & 1.008 & 1.011 \\
\hline$R(\mathrm{I}>2 \sigma(\mathrm{I}))$ & 0.0247 & 0.0488 \\
\hline$R($ all data $)$ & 0.0358 & 0.0513 \\
\hline$\Delta \rho_{\max }$ and $\Delta \rho_{\min }, \mathrm{e}^{3}$ & 2.505 and -0.941 & 1.926 and -1.582 \\
\hline
\end{tabular}

\section{Acknowledgements}

The research described in this publication was made possible in part by CSSDT (\#08.819.05.01F) and SNF (SCOPES IB\#7320-110823) grants. S.Melnic is grateful to the World Science Foundation. Authors are grateful for providing of magnetic data $(\mathbf{5}, \mathbf{1 0})$ to the group of Prof. A. K. Powell (University of Karlsruhe, Germany).

\section{References}

[1]. Caneschi, A.; Dei, A.; Gatteschi, D.; Poussereau, S.; Sorace, L. Dalton Trans. 2004, 1048-1055.

[2]. Li, X.; Zhang, Z.-Y.; Zou, Y.-Q. Eur. J. Inorg. Chem. 2005, 2909-2918.

[3]. Rohde, A.; Urland, W. Inorg. Chim. Acta. 2006, 359, 2448-2454.

[4]. Kido, T.; Ikuta, Y.; Sunatsuki, Y.; Ogawa, Y.; Matsumoto, N. Inorg. Chem. 2003, 42, 398-408.

[5]. Benelli, C.; Gatteschi, D. Chem. Rev. 2002, 102, 2369-2388.

[6]. Figuerola, A.; Diaz, C.; Ribas, J.; Tangoulis, V.; Granell, J.; Lloret, F.; Mahia, J.; Maestro, M. Inorg. Chem. 2003, 42, 641-649.

[7]. Yin, M.; Lei, X.; Li, M.; Yuan, L.; Sun, J. J. Phys. Chem. Solids. 2006, 67, 1372-1378.

[8]. Turta, C.; Melnic, S.; Bettinelli, M.; Shova, S.; Benelli, C.; Speghini, A.; Caneschi, A.; Gdaniec, M.; Simonov, Y.; Prodius, D.; Mereacre, V. Inorg. Chim. Acta. 2007, 9, 3047-3054.

[9]. Allen, F.N. Acta Crystallogr., Sect.B: Struct.Sci. 2002, 58(2), 380-388.

[10]. Paluchowska, B.; Maurin, J. K.; Leciejewicz, J. Acta Cryst. 1997, C53, 287-289.

[11]. Novitski, G.; Borta, A.; Shova, S.; Kazeva, O.N.; Gdaniec, M.; Simonov, Yu. A. Russ. J. Inorg. Chem. 2008, $53,202-208$.

[12]. Lam, A. W.-H.; Wong, W.-T.; Gao, S.; Wen, G.; Zhang, X.-X. Eur. J. Inorg. Chem. 2003, 149-163.

[13]. Rohde, A.; Hatscher, S.T.; Urland, W. J. Alloys Compd. 2004, 374, 137-141.

[14]. Rohde, A.; Urland, W. Z. Anorg. Allg.Chem. 2004, 630, 2434-2437.

[15]. John, D.; Urland, W. Eur. J. Inorg. Chem. 2005, 4486-4489.

[16]. John, D.; Urland, W. Z. Anorg. Allg.Chem. 2005, 631, 2635-2637.

[17]. Rohde, A.; Urland, W. Dalton Trans. 2006, 2974-2978.

[18]. Costes, J.-P.; Clemente-Juan, J.-M.; Dahan, F.; Necodeme, F.; Verelst, M. Angew. Chem., Int. Ed. 2002, 41, 323-325.

[19]. Hou, H.; Li, G.; Li, L.; Zhu, Y.; Meng X.; Fan, Y. Inorg. Chem. 2003, 42, 428-435.

[20]. Hatscher, S.T.; Urland, W. Angew. Chem., Int. Ed. 2003, 42, 2862-2864.

[21]. (a) Costes, J.-P.; Clemente-Juan, J.-M.; Dahan, F.; Necodeme, F. Dalton Trans. 2003, 1272-1275; (b) Xu, N.; Shi, W.; Liao, D.-Z.; Yan, S.-P.; Cheng, P. Inorg. Chem. 2008, 47, 8748-8756.

[22]. Hernandez-Molina, M.; Ruiz-Perez, C.; Lopez, T.; Lloret F.; Julve, M. Inorg. Chem. 2003, 42, 5456-5458.

[23]. Rohde, A.; Urland, W. Z. Anorg. Allg.Chem. 2005, 631, 417-420.

[24]. Rohde, A.; Urland, W. J. Alloys Compd. 2006, 408-412, 618-621.

[25]. Kahn, O. Molecular Magnetism; VCH Publishers. New York, Weinheim, Cambridge, 1993, p.380.

[26]. Armarego, L. F.; Perrin, D. D. Purification of Laboratory Chemicals, Butterworth-Heinemann, Oxford, 4th ed., 1996, p.529.

[27]. CrysAlis CCD and CrysAlis RED ver. 168, KUMA Diffraction Instruments GmbH, 2001.

[28]. STOE, IPDS Manual. Version 2.93. Stoe \& Cie, Darmstadt,Germany, 1997.

[29]. Sheldrick, G. M. SHELX86, Acta Crystallogr. 46A, 1990, 467.

[30]. Sheldrick, G. M. SHELXL-97, University of Göttingen: Göttingen, 1997.

[31]. XEMP ver. 4.2. Siemens Analytical X-ray Inst. Inc. 1990.

[32]. International Tables for Crystallography, vol. C, Kluwer Academic Publishers, Dordrecht, Netherlands, 1992, p.622.

[33]. Zsolnai, L.; Pritzkow, H.; Huttner, G. ZORTEP. Ortep for PC, Program for Molecular Graphics, University of Heidelberg, Heidelberg, Germany, 1996. 